\title{
Modeling Smart Homes for Prediction Algorithms
}

Conference Paper · September 2007

DOI: 10.1007/978-3-540-74827-4_4· Source: DBLP

CITATIONS

5

6 authors, including:

Alejandro Fernández-Montes

Universidad de Sevilla

50 PUBLICATIONS 305 CITATIONS

SEE PROFILE

Juan A. Ortega

Universidad de Sevilla

190 PUBLICATIONS 912 CITATIONS

SEE PROFILE
READS

156

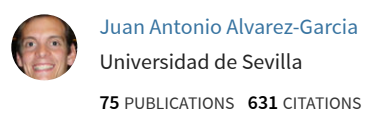

75 PUBLICATIONS 631 CITATIONS

SEE PROFILE

Luis Gonzalez-Abril

Universidad de Sevilla

247 PUBLICATIONS 1,196 CITATIONS

SEE PROFILE

Some of the authors of this publication are also working on these related projects:

REACT: EneRgy efficiency and pErformAnCe of data centers by smart virTuallzation and deep learning event detection.

View project

Project $\quad$ Energy Expenditure Estimation View project 


\title{
Modeling Smart Homes for Prediction Algorithms
}

\author{
A. Fernández-Montes, J.A. Álvarez, J.A. Ortega, M.D. Cruz, L. González, \\ and F. Velasco \\ Departamento de lenguajes y sistemas informáticos. ETSI Informática Avda. Reina \\ Mercedes s/n, Sevilla \\ alejandro.fdez@gmail.com, jaalvarez@us.es, ortega@lsi.us.es, \\ manuel3086@gmail.com, velasco@us.es, luisgon@us.es
}

\begin{abstract}
This paper reviews the goals of the Domoweb project and the solutions adopted to achieve them. As a result we enjoy a great support to develop smart home techniques and solutions. As a consequence of the acquired experiences a Smart home model is proposed as a division of four main categories. In relation with the smart home model, we show the essential features a smart environment prediction algorithm should satisfy and a procedure to select relevant information from the model to achieve artificial intelligence based solutions.
\end{abstract}

\section{Introduction}

Smart home technologies are often included as a part of ubiquitous computing. Mark Weiser [1] outlined some principles to describe Ubiquitous Computing (ubicomp) from which we emphasize that the purpose of a computer is to help you do something else.

Home technologies have tried to help home inhabitants since its creation. Nowadays, due to the popularization of computational devices, ubiquitous computing is called to be the revolution to develop smart systems with artificial intelligence techniques.

Domoweb [2] is a research project which was originally developed as a residential gateway implementation over the OSGi (Open Services Gateway Initiative) service platform. Domoweb implements the standard services any residential gateway must have like http server, web interfaces, device manager, user manager and other basic services.

Nowadays Domoweb conform a great platform where researchers from different disciplines converges and where we can deploy, develop and test smart home related solutions, due to the component based model, and the service oriented architecture that Domoweb and OSGi supports.

This article focuses on modeling smart homes and the features the prediction algorithms should implement. A good smart environment model must represent the 
properties, states, attributes and any other characteristic that could be useful in building smart environments solutions as is proposed in section 2 .

Artificial intelligent methods can be supported by this model like prediction algorithms where is centered this article. The features these algorithms must be aware of are defined in section 3 and finally a procedure to discriminate significant information is released in section 4.

\section{Smart Home Model}

Artificial intelligence algorithms need a solid base of knowledge to work. This fact demands us a great effort for building a model of the smart home and its environment. Other projects have helped us to compose the model [3-5] which has been arranged in four main categories explained in next sections and expounded in table 1.

\subsection{Device Related}

This category is the most obvious one so is related with the main elements in a smart home environment. Ambient intelligence algorithms should be aware of next main fields:

- Status. Algorithms must know the current states of devices installed on the smart home. Obviously this is essential for these algorithms, and one of the most important domains to build future predictions.

- Location. Devices usually occupy a location for a long time and this location may be useful for ambient intelligence algorithms. The model must be able to consider non-still devices as well, like motorized cleaner robots and others.

\subsection{Inhabitants Related}

Smart home algorithms must be aware of the inhabitants' status to offer appropriate predictions for any user or for the whole group of inhabitants. On this line we discuss some of the necessary fields to infer inhabitants-aware predictions:

- Personal data. This field includes all the data concerning to a particular person like name, age, sex and so on.

- Location. Inhabitants can move over the home rooms, so smart home systems have to know where each inhabitant is, and should be able to identify them.

- Physical state. This field is related with the illness or injuries that an inhabitant can suffer during his life. Smart home technologies must adapt to this situations and offer appropriate replies.

- Mental state. The state of mind of a person can be defined as a temporary psychological state. A depressed inhabitant behavior usually differs from a euphoric one, so smart home must be consistent with these circumstances. 
Table 1. Smart Home Model

\begin{tabular}{|c|c|c|c|}
\hline CATEGORIES & FIELDS & DESCRIPTION & EXAMPLE \\
\hline \multirow[t]{2}{*}{ DEVICE RELATED } & Status & $\begin{array}{l}\text { Current state the } \\
\text { devices are. }\end{array}$ & $\begin{array}{l}\text { Sensor } \\
\text { temperature is at } \\
25^{\circ} \mathrm{C}\end{array}$ \\
\hline & Location & $\begin{array}{l}\text { Where the devices } \\
\text { are. }\end{array}$ & $\begin{array}{l}\text { Cleaner robot is } \\
\text { in Living room. }\end{array}$ \\
\hline \multirow{4}{*}{$\begin{array}{l}\text { INHABITANTS } \\
\text { RELATED }\end{array}$} & Personal data & Name, Age, sex. & Diane is 45 . \\
\hline & Location & $\begin{array}{l}\text { Where the } \\
\text { inhabitants are. }\end{array}$ & $\begin{array}{l}\text { Mark is at } \\
\text { bedroom. }\end{array}$ \\
\hline & \begin{tabular}{|l|} 
Physical state \\
\end{tabular} & $\begin{array}{l}\text { Illness, injuries, and } \\
\text { others states } \\
\text { inhabitants are. }\end{array}$ & Roy has a cold. \\
\hline & Mental state & $\begin{array}{l}\text { Psychological state } \\
\text { the inhabitants are. }\end{array}$ & $\begin{array}{l}\text { David is } \\
\text { depressed. }\end{array}$ \\
\hline \multirow{2}{*}{$\begin{array}{l}\text { ENVIRONMENT } \\
\text { RELATED }\end{array}$} & Date, time & $\begin{array}{l}\text { Temporary } \\
\text { information }\end{array}$ & $\begin{array}{l}\text { Current time is } \\
13: 36 \text {. }\end{array}$ \\
\hline & $\begin{array}{l}\text { Environmental } \\
\text { conditions }\end{array}$ & $\begin{array}{l}\text { the phenomena that } \\
\text { currently occur in } \\
\text { the atmosphere }\end{array}$ & It's rainy \\
\hline \multirow[b]{2}{*}{ HOME BACKGROUND } & $\begin{array}{l}\text { Inert entities } \\
\text { location }\end{array}$ & $\begin{array}{l}\text { Where these entities } \\
\text { are. }\end{array}$ & $\begin{array}{l}\text { Sofa is at living } \\
\text { room. }\end{array}$ \\
\hline & $\begin{array}{l}\text { Home limits } \\
\text { properties }\end{array}$ & $\begin{array}{l}\text { The properties of } \\
\text { the home structure } \\
\text { and limits. }\end{array}$ & $\begin{array}{l}\text { Bedroom } \\
\text { window opacity } \\
\text { is } 70 \%\end{array}$ \\
\hline
\end{tabular}

\subsection{Environment Related}

This category probably is the most diffused due to it covers heterogeneous and difficult-to-limit fields as we discuss in the following list: 
- Date, time, season. Obviously smart home behavior should be different in different temporal conditions and it may depend in these temporal factors as the air condition policies will differ between summer and winter.

- Environmental conditions. This field comprises current environmental conditions (sunny, cloudy, rainy and others). Smart home should make a request for a weather forecast as well, which could be significant to assess future decisions.

\subsection{Home Background}

This category must comprise all the relevant things concerned to inert entities and its properties or qualities. This could be the less relevant category discussed, but anyway could be significant in some concrete applications. We propose a couple of fields related in next listing:

- Furniture location and position. Furniture occupies space at home and can be moved. Location (room where the furniture is) and position (place where the furniture is placed in a room) should be known by the smart home systems due to it could be useful by concrete applications like robot movement related algorithms, or presence detection related algorithms.

- Home limits properties. The texture of a floor, the color of a wall, or the opacity of the windows could be significant in several cases such as temperature adjustment applications.

\section{Features of Prediction Algorithms}

In this section we present the features that a smart home system must implement, specially related with the prediction algorithms the systems may have. The article doesn't focuses on artificial intelligence techniques like the studies of [5-10] do, but on what are the most important and indispensable features that must be considered to develop prediction algorithms. Much of the ideas presented below could be useful to implement others smart home algorithms.

\subsection{Prediction Supported by Last Events and States}

Prediction algorithms should consider as input data two main aspects. First it should analyze the last events occurred in the home's performance field which have changed the home status in any manner.

Second it should analyze current state and previous states as well. This way the algorithms should determine last changes in the home status, and which events have been involved in these changes.

In section 5 we discuss further about these aspects and propose a way to consider states and events. 


\subsection{Predictable by the Inhabitants}

Smart homes should learn inhabitant behaviors and habits, and build predictions, but it has to be predictable by the inhabitants to achieve no unexpected behaviors.

\subsection{Understandable Decisions}

Prediction algorithms have to offer an explanation of their predictions and/or actions. This way the inhabitants will be more trusted with the decisions the system took. This will improve the user acceptance of the smart home predictions.

\subsection{Wrong Decisions Detection and Related Improvement}

If the smart home executes a wrong decision it should be aware of this failure and be able to learn from its errors. A possible scenario should be when someone arrives home at night and the system orders the hall lights to switch on, but immediately the user performs the opposite action (which should be switch off the lights). The system has to notice this failure and extract some knowledge from this experience to face future similar situations with guarantees of success.

\subsection{Anomalies Detection}

In some scenarios, the smart home should consider that a wrong decision executed as a consequence of a wrong prediction could be produced due to an anomaly. We can consider this scenario, an inhabitant wake up all working days at 7.00 a.m., so smart home switch on the coffee-maker some minutes before. But when the wake-up alarm goes off, the smart home detects no movement so it could be desirable to request an emergency service with a standard phone call or other mechanism.

\subsection{Quick Response When Required}

Some situations require the smart home prediction algorithms to return a response with time limits. These algorithms are responsible for detection of this situations and they must be able to adapt to these circumstances in order to provide a quick response.

\subsection{General Policies and User Adaptation}

Smart homes technologies should implement the mechanisms to support some home policies like security, energy or comfort. These policies can be collected in different levels. The inhabitants could define some general policies which could be customizable by concrete inhabitant preferences. We can discuss the following scenario; inhabitant A gives preference to energy consumption over comfort. To satisfy these preferences smart home system should try to minimize the energy 
consumption produced as a result of its predictions. On the other hand, inhabitant B gives preference to comfort over energy consumption, so algorithm has to adapt to this user preferences policy.

This way if the prediction algorithm determines that inhabitant A arrives home, it will switch on air conditioner system only at the arrival of the inhabitant, however if the inhabitant B is going to arrive home, the smart home should switch on the air conditioner system sometime before the arrival of the inhabitant.

\section{Window of States}

Smart home prediction algorithms usually make use of last states and events occurred at home environment. A state can be defined as the whole set of pairs field-value according to the model presented in section 3. We could also distinguish subsets of these states for each category so we shape the related sub-states. This way we can consider sub-states to include devices related, inhabitants related, environment related and background related information.

Events can be defined as something that happen at a given place and time. In smart home contexts, we can add to this definition that the event must cause a state change of the smart home. Events that do not cause a state change shouldn't be considered by smart home algorithms as something significant.

When building a smart home solution we can discuss what states and events should be considered. To resolve this situation we propose the use of a window which envelops the states (and events) that are going to take part in the giving response as shown in figure 2.

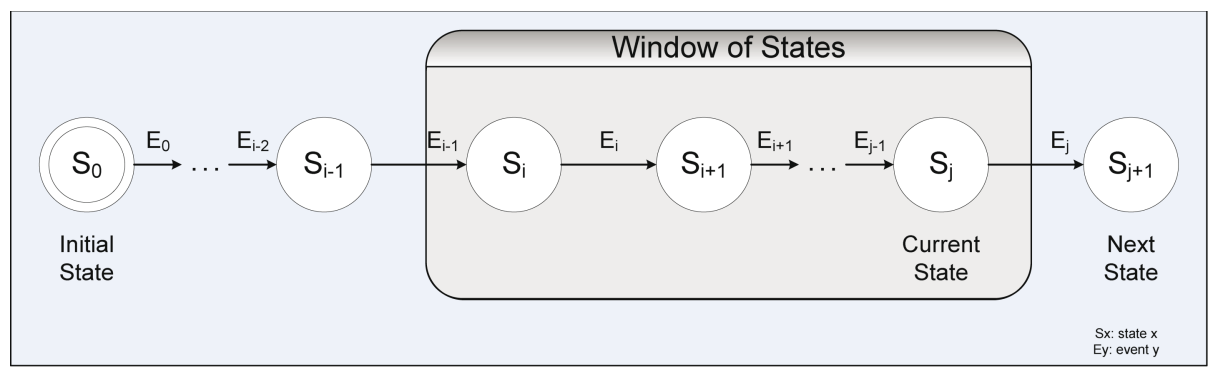

Fig. 1. Window of states

States are represented as circumferences labeled from $S_{0}$ to $S_{j+1}$, transitions between states as arrows labeled with the event which caused the state change.

Reader should notice that states from $S_{0}$ (initial state) to $S_{j-1}$ are past time states, $\mathrm{S}_{\mathrm{j}}$ is the current state and $S_{j+l}$ is the next state which is currently unknown.

The size of the window $\boldsymbol{n}$ equals to the number of states and events to be processed. This size is deduced from the equation $\boldsymbol{n}=\boldsymbol{j}-\boldsymbol{i}+\boldsymbol{1}$. 


\subsection{Dynamic vs. Static Window}

Two approaches can be considered related with the size of the window. Algorithms designer could prefer the use of a static and predefined size of this window to build smart predictions. This approach can be useful in non-complex solutions, so it's easy to implement. The size could be estimated by means of empirical techniques and the own designer experience.

However dynamic window size is a more powerful approach for determining the size in real time. Algorithms could extend and reduce the size of the window depending on the requisites of current application like time of processing, hardware capabilities, solution accuracy and others.

\section{Conclusions and Future Work}

The previous sections have discussed some basis related with smart environments methods. A first model approach have been proposed as a start point to develop successful solutions, and prediction algorithms features form a guideline to implement these algorithms.

Prediction algorithms promise to be applicable to many areas within the smart home and smart environments so future work should be centered in the study of the methods and artificial intelligence techniques for prediction as in the improvement of the model definition.

Acknowledgements. This research is supported by the MEC I+D project InCare. Ref: TSI2006-13390-C02-02.

\section{References}

[1] Weiser, M.: The computer for the 21st century. Scientific American 265(3), 66-75 (1991)

[2] Álvarez, J.A., Cruz, M.D., Fernández, A., Ortega, J.A., Torres, J.: Experiencias en entornos de computación ubica mediante arquitecturas orientadas a servicios. In: JSWEB 2005 (W3C) (2005)

[3] Cook, D.J., Youngblood, M., Das, S.K.: A Multi-agent Approach to Controlling a Smart Environment. Designing Smart Homes, 165-182 (2006)

[4] Li, J., Bu, Y., Chen, S., Tao, X., Lu, J.: FollowMe: On Research of Pluggable Infrastructure for Context-Awareness. In: Proceedings of the 20th International Conference on Advanced Information Networking and Applications, IEEE, Los Alamitos (2006)

[5] Das, S.K., Cook, D.J.: Designing Smart Environments: A Paradigm Based on Learning and Prediction. In: Pal, S.K., Bandyopadhyay, S., Biswas, S. (eds.) PReMI 2005. LNCS, vol. 3776, Springer, Heidelberg (2005)

[6] Leake, D., Maguitman, A., Reichherzer, T.: Cases, Context, and Comfort: Opportunities for Case-Based Reasoning in Smart Homes. Designing Smart Homes, 109-131 (2006)

[7] Hagras, H., Callaghan, V., Colley, M., Clarke, G., Pounds-Cornish, A., Duman, H.: Creating an ambient-intelligence environment using embedded agents. IEEE Intelligent Systems 19 (2004) 
[8] Choi, J., Shin, D., Shin, D.: Research on Design and Implementation of the Artificial Intelligence Agent for Smart Home Based on Support Vector Machine. In: Wang, L., Chen, K., Ong, Y.S. (eds.) ICNC 2005. LNCS, vol. 3610, Springer, Heidelberg (2005)

[9] Roy, N., Roy, A., Das, S.K.: Context-Aware Resource Management in Multi-Inhabitant Smart Homes:A Nash H-Learning based Approach. In: IEEE PERCOM'06 (2006)

[10] Yamazaki, T.: Beyond the Smart Home. In: ICHIT'06 (2006)

[11] Jiang, L., Llu, D.-Y., Yang, B.: Smart home research. In: Proceedings of the Third International Conference on Machine Learning and Cybernetics, Shanghai, pp. 26-29 (2004) 